\title{
Quantificação de compostos fenólicos e ácido ascórbico em frutos e polpas congeladas de acerola, caju, goiaba e morango
}

\author{
Quantification of phenolic compounds and ascorbic acid in fruits and frozen \\ pulp of acerola, cashew, strawberry and guava
}

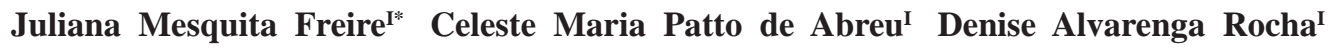 \\ Angelita Duarte Corrêa ${ }^{\mathrm{I}}$ Natália Rodrigues Marques $^{\mathrm{I}}$
}

RESUMO

\begin{abstract}
O crescente interesse da população pela promoção da saúde vem despertando a atenção dos consumidores por alimentos ricos em antioxidantes, combinado com a praticidade do consumo de sucos de frutos processados. O presente trabalho objetivou quantificar e avaliar a capacidade antioxidante de compostos fenólicos e ácido ascórbico em frutas in natura e polpas congeladas. As frutas in natura e polpas congeladas obtidas na região de Lavras - MG foram submetidas à quantificação de compostos fenólicos e ácido ascórbico e os respectivos extratos acetônico-etanólico e acetônico-metanólico. Foram determinadas suas atividades antioxidantes pelos métodos radicalares DPPH e ABTS. O extrato acetônico-metanólico foi mais efetivo para extrair os compostos antioxidantes das amostras. Apenas as polpas congeladas de acerola apresentaram uma redução do teor de compostos fenólicos em relação ao fruto. Para o teor de ácido ascórbico, houve uma redução nas polpas congeladas de acerola e goiaba. As amostras de acerola apresentaram os maiores teores de compostos fenólicos, ácido ascórbico e atividade antioxidante em relação aos demais frutos analisados.
\end{abstract}

Palavras-chave: frutos in natura, polpas congeladas, atividade antioxidante e compostos fenólicos.

\section{ABSTRACT}

The growing public interest in health- promotion, has called the attention of consumers for foods rich in antioxidants, combined with the practicality of the consumption of processed fruit juices. Therefore, this study aimed to quantify and evaluate the antioxidant capacity of phenolic compounds and ascorbic acid in fruits "in natura" and frozen pulps. The fruits "in natura" and frozen pulps from region of Lavras-MG, underwent quantification of phenolic compounds, ascorbic acid and the corresponding extracts acetonic-ethanolic and acetonic-methanolic. Their antioxidant activities were evaluated by DPPH and ABTS radical methods. The extract acetonic-methanolic was more effective to extract the antioxidant compounds from samples. Only frozen acerola pulps showed lower content of phenolic compounds in relation to fruit. For ascorbic acid, there was a reduction in the frozen pulp of acerola and guava. Acerola samples showed higher content of phenolic compounds, ascorbic acid and antioxidant activity compared to other fruits analyzed.

Key words: fresh fruits, frozen pulps, antioxidant activity, phenolic compound.

\section{INTRODUÇÃO}

Os antioxidantes são compostos químicos que podem prevenir ou diminuir os danos oxidativos de lipídios, proteínas e ácidos nucleicos causados por espécies de oxigênio reativo. Essas espécies geradas no organismo são os responsáveis por danos celulares, conduzindo a várias anormalidades fisiológicas e patológicas, tais como inflamação, doenças cardiovasculares, câncer e envelhecimento.

Recentes estudos indicam que o consumo de frutos está associado com a redução da mortalidade e morbidade, causadas por doenças crônicas. Esse efeito se deve aos compostos antioxidantes presentes em várias partes das frutas e hortaliças denominadas antioxidantes exógenos. Entre eles, estão o ácido ascórbico, carotenoides e os compostos fenólicos, que são encontrados em diferentes concentrações nos frutos. Os antioxidantes endógenos são as enzimas (catalase, glutationa peroxidase e superóxido dismutase) presentes no organismo, responsáveis pelo metabolismo e controle da homeostasia deste.

'Departamento de Química, Laboratório de Bioquímica, Universidade Federal de Lavras (UFLA), Lavras, MG, Brasil. E-mail: mesquitafreire@yahoo.com.br. *Autor para correspondência. 
Para avaliar a capacidade antioxidante de um fruto, faz-se necessário extrair o máximo de compostos antioxidantes. Muitos fatores, tais como: tipos de solvente, tempo de extração, temperatura, $\mathrm{pH}$, proporção sólido-líquido e tamanho das partículas influenciam na extração. A polaridade do solvente é o fator mais importante, pois compostos fenólicos apresentam polaridade diferenciada entre eles. Dessa forma, a solubilidade em um determinado solvente é característica peculiar do fitoquímico, o que explica a inexistência de um procedimento de extração universal (MELO et al., 2008).

O hábito do consumo de sucos de frutos processados tem aumentado, motivado pela falta de tempo da população em preparar suco dos frutos in natura, pela praticidade oferecida pelos produtos, substituição ao consumo de bebidas carbonatadas devido ao seu valor nutritivo e a preocupação com o consumo de alimentos mais saudáveis. Tendo em vista a importância que os frutos in natura e os processados representam à economia e à dieta dos brasileiros, e a importância de pesquisas por antioxidantes naturais, este trabalho teve o objetivo de quantificar compostos fenólicos e ácido ascórbico, além de avaliar a atividade antioxidante nos frutos de acerola, caju, goiaba e morango e suas respectivas polpas congeladas, de significado comercial no Brasil, bem como comparar a eficiência de duas misturas de solventes para a extração dos compostos antioxidantes.

\section{MATERIAL E MÉTODOS}

Matéria prima

Os frutos de acerola (Malpighia emarginata), caju (Anacardium occidentale), goiaba (Psidium guajava) e morango (Fragaria sp) foram adquiridos no comércio local da cidade de Lavras/ MG. Os frutos foram higienizados e divididos em dois lotes. Ambos foram triturados. Os teores de ácido ascórbico, compostos fenólicos e a atividade antioxidante do primeiro lote foram analisados no dia do processamento. $\mathrm{O}$ segundo lote foi armazenado em freezer $\left(-18^{\circ} \mathrm{C}\right)$ por um período de 3 meses e, posteriormente, submetido às análises. Os experimentos foram realizados em delineamento inteiramente casualizado, com 8 tratamentos e 4 repetições. Os resultados foram submetidos à análise de variância, por meio do programa Sisvar. As médias foram comparadas entre si pelo teste de Scott-Knott, a 5\% de significância.

Determinação dos compostos fenólicos

A extração foi realizada na proporção de $3 \mathrm{~g}$ de amostra diluída em $250 \mathrm{~mL}$ de metanol $50 \%$, em refluxo por três vezes consecutivas a $80^{\circ} \mathrm{C}$ e os extratos reunidos, evaporados até $25 \mathrm{~mL}$ (GOLDSTEIN \& SWAIN, 1963). Os compostos foram submetidos à dosagem utilizando-se o reagente de Folin-Denis e medido a 760nm (AOAC, 2005). Os resultados foram expressos em mg de ácido tânico $\mathrm{g}^{-1}$ amostra.

\section{Determinação da atividade antioxidante}

A extração foi realizada segundo RUFINO et. al. (2007), com modificações, utilizando acetona/ metanol (30/70) ou acetona/etanol (30/70) na proporção de $3 \mathrm{~g}$ de amostra para $25 \mathrm{~mL}$ do extrator $\left(0,12 \mathrm{~g} \mathrm{~mL}^{-1}\right)$. Esses foram submetidos à agitação em temperatura ambiente por 60 minutos e centrifugados por 15 minutos. O sobrenadante foi transferido para um balão volumétrico de $25 \mathrm{~mL}$ e o volume completado com o solvente extrator. A partir dos extratos obtidos, foram feitos quatro diluições diferentes para a construção da equação da reta.

\section{Método DPPH}

A capacidade de sequestrar o radical DPPH (1,1-difenil-2-picrilhidrazil) foi realizada segundo THAIPONG et al. (2006), com modificações. Alíquotas de $0,1 \mathrm{~mL}$ de cada diluição foram adicionadas a $3,9 \mathrm{~mL}$ da solução de $\mathrm{DPPH}$ em metanol $(0,06 \mathrm{mM})$. Ao final de 30 minutos, a absorbância foi medida a $515 \mathrm{~nm}$ e a capacidade de sequestrar o radical calculada em relação ao controle (sem antioxidante), segundo a expressão abaixo:

\% sequestros $=$ Absorbância do controle - Absorbância da amostrax $100 \%$

Absorbância do controle

Através da equação da reta, foram calculadas as concentrações $\left(\mathrm{mg} \mathrm{mL}^{-1}\right)$ necessárias para inibir $50 \%$ do radical $\mathrm{DPPH}^{\circ}$. O antioxidante sintético butilhidroxitolueno (BHT) e a quercetina foram utilizados como padrão, e foram submetidos às mesmas condições.

\section{Método ABTS}

A capacidade antioxidante foi determinada pela redução do radical livre $\mathrm{ABTS}^{++}\left(2,2^{\prime}\right.$ - azinobis(3etilbenzotiazolina-6-ácido sulfônico)) através dos antioxidantes presentes nas amostras, de acordo com o método modificado por THAIPONG et al. (2006). Alíquotas de $150 \mu \mathrm{L}$ de cada diluição foram adicionadas a $2850 \mu \mathrm{L}$ de $\mathrm{ABTS}^{\cdot+}(7,4 \mathrm{mM})$. Após 6 minutos, foi realizada a leitura no espectrofotômetro em 734nm. Os resultados foram expressos em $\mu \mathrm{M}$ trolox $\mathrm{g}^{-1}$ amostra (atividade antioxidante equivalente ao trolox-TEAC (vitamina E) e mg ácido ascórbico 
$\mathrm{g}^{-1}$ amostra (atividade antioxidante equivalente ao ácido ascórbico-VCEAC). $\mathrm{O}$ antioxidante sintético BHT e a quercetina foram utilizados como padrão, e foram submetidos às mesmas condições.

Determinação do ácido ascórbico

A extração foi realizada segundo STROHECKER \& HENNINGG (1967), sendo os extratos filtrados em membrana Millipore de $0,22 \mu \mathrm{m}$ antes da análise cromatográfica. Foi utilizado um cromatógrafo líquido da marca Shimadzu LC 20A, detector UV-Vis, sendo os cromatogramas a $254 \mathrm{~nm}$; bomba quaternária, desgaseificador e injeção automática. Foi utilizada coluna C18 Nucleosil $(250 \times 4,6 \mathrm{mmx} 5 \mu \mathrm{m})$. Como fase móvel, foi utilizado um tampão de $\mathrm{pH}$ de 6,7 , contendo acetato de sódio $0,004 \mathrm{~mol} \mathrm{~L}^{-1}$, EDTA $0,05 \mathrm{~mol} \mathrm{~L}^{-1}$, fosfato de tributilamônio $0,5 \mathrm{~mol} \mathrm{~L}^{-1} \mathrm{de}$ modo isocrático, com fluxo de $0,6 \mathrm{ml} \mathrm{min}^{-1}$, com um tempo de corrida de 15 minutos para cada amostra (SILVA et al., 2009). Foi feita uma curva analítica com 10 pontos, em duplicada.

\section{RESULTADOS E DISCUSSÃO}

Na tabela 1, apresentam-se os teores dos compostos fenólicos e ácido ascórbico das frutas e suas polpas congeladas. As amostras de acerola in natura e congelada apresentaram os maiores teores de compostos fenólicos, quando comparadas com as demais amostras, sendo significativa essa diferença. $\mathrm{O}$ teor de compostos fenólicos nos frutos de acerola in natura foi significativamente maior do que o encontrado na polpa congelada. Os frutos "in natura" e polpas congeladas de caju e morango não apresentaram diferença significativa nos teores de compostos fenólicos. Os menores teores foram encontrados para as amostras de goiaba, sem diferença significativa entre os frutos in natura e polpa congelada.

Evidencia-se que o armazenamento sob congelamento promoveu uma redução de 27,53\%, $5,65 \%$ e $4,97 \%$ no teor de compostos fenólicos totais nas polpas de acerola, caju e morango, respectivamente, enquanto, na polpa da goiaba, ocorreu um aumento de $20,51 \%$ desses constituintes. Porém, apenas para a acerola essa redução foi significativa.

KUSKOSKI et al. (2006), estudando as polpas congeladas de acerola, morango e goiaba, encontraram 5,8; 1,32 e 0,83mg fenólico, equivalente a ácido gálico $\mathrm{g}^{-1}$, respectivamente. A extração foi realizada diluindo-se $100 \mathrm{~g}$ de amostra em $250 \mathrm{ml}$ de água. No trabalho de MELO et al. (2008), as polpas congeladas de acerola, caju e goiaba apresentaram os seguintes teores de fenólicos: 7,88; 5,14; e 1,40mg fenólicos equivalentes catequina $\mathrm{g}^{-1}$, respectivamente, utilizando o metanol $80 \%$ como extrator por 20 minutos à temperatura ambiente. Essas variações de teores podem ser decorrentes das características ambientais de cultivo, variedade da cultivar, processamento e maturidade dos frutos, além das condições utilizadas para a extração dos compostos fenólicos, como solventes utilizados, temperatura e tempo de extração, que também podem afetar os resultados obtidos (KUSKOSKI et al., 2006; MELO et al., 2008).

De acordo com a tabela 1, observa-se que o fruto acerola apresentou os maiores teores de ácido ascórbico, sendo essa diferença significativa em relação aos outros frutos. Para as amostras de caju e morango, não foram observadas diferenças significativas no teor de ácido ascórbico entre os frutos in natura e polpa congelada, embora tenha

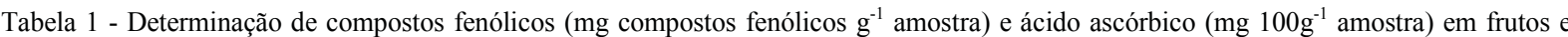
polpas congeladas de acerola, caju, goiaba e morango.

\begin{tabular}{lcc}
\hline Amostras & Compostos fenólicos & Ácido ascórbico \\
\hline Acerola in natura & $14,89 \pm 1,01 \mathrm{a}$ & $1457,69 \pm 279,92 \mathrm{a}$ \\
Acerola polpa congelada* & $10,79 \pm 0,31 \mathrm{~b}$ & $778,10 \pm 74,11 \mathrm{~b}$ \\
Caju in natura & $2,48 \pm 0,15 \mathrm{c}$ & $219,00 \pm 29,48 \mathrm{c}$ \\
Caju polpa congelada* & $2,34 \pm 0,11 \mathrm{c}$ & $153,00 \pm 43,99 \mathrm{c}$ \\
Morango in natura & $2,41 \pm 0,02 \mathrm{c}$ & $71,80 \pm 9,22 \mathrm{~d}$ \\
Morango polpa congelada* & $2,29 \pm 0,00 \mathrm{c}$ & $44,40 \pm 8,55 \mathrm{~d}$ \\
Goiaba in natura & $1,24 \pm 0,04 \mathrm{~d}$ & $218,00 \pm 45,77 \mathrm{c}$ \\
Goiaba polpa congelada* & $1,56 \pm 0,06 \mathrm{~d}$ & $69,70 \pm 2,71 \mathrm{~d}$ \\
\hline
\end{tabular}

Médias seguidas da mesma letra minúscula não diferem entre si pelo teste de Scott-Knott ( $5 \%$ de probabilidade). Médias \pm desvio padrão de 4 repetições. ${ }^{*}$ Polpas congeladas a $-18^{\circ} \mathrm{C}$ por 3 meses. 
sido observada uma redução nos teores para as polpas congeladas. Já para as amostras de acerola e goiaba, os frutos in natura apresentaram teores significativamente maiores que as suas respectivas polpas congeladas. Essa redução foi de 46,62\%, $38,10 \%, 38,07 \%$ e $69,82 \%$ para as polpas congeladas de acerola, caju, morango e goiaba, respectivamente, quando comparada aos seus frutos in natura. A redução no teor de ácido ascórbico para este estudo se deve principalmente ao efeito do armazenamento e aplicação, pois essa vitamina é suscetível à degradação. Outros fatores que também influenciam na sua degradação são o calor, oxidação, dessecação e alcalinidade do meio.

Dados da literatura para os teores de ácido ascórbico para as amostras de acerola, caju e morango

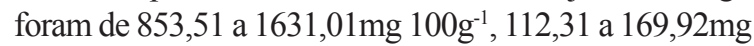
$100 \mathrm{~g}^{-1}$ e 57,14 a $81,14 \mathrm{mg} 100 \mathrm{~g}^{-1}$, respectivamente, concordando com os resultados deste estudo, com exceção para a polpa congelada de morango que apresentou teor inferior (GOMES et al., 2000; PIMENTEL et al., 2001; LIMA et al., 2007 \& ROCHA et al., 2008).

Observa-se (Tabela 2) que as amostras de acerola apresentaram uma maior atividade antioxidante, com os valores de $\mathrm{IC}_{50 \%}$ variando entre 0,179 a $0,286 \mathrm{mg} \mathrm{mL}^{-1}$, o que pode ser justificado pelo maior teor de compostos fenólicos e ácido ascórbico encontrado para esse fruto (Tabela 1). Ao comparar as frutas in natura com suas respectivas polpas congeladas (Tabela 2), observa-se que, para o extrato acetônico-etanólico, houve diferença significativa, sendo que para as amostras de acerola, morango e goiaba os frutos in natura apresentaram maior atividade antioxidante. Já na amostra de caju a atividade antioxidante foi superior para a polpa congelada. Analisando os extratos acetônicometanólicos, observa-se que apenas no caju a polpa congelada apresentou maior atividade antioxidante, quando comparado ao fruto in natura e na acerola não houve diferença significativa.

Quando se compara a atividade antioxidante dos dois tipos de extratores, observa-se (Tabela 2) que, com exceção da amostra de polpa congelada de morango, os extratos acetônico-metanólicos apresentaram maior atividade antioxidante que os extratos acetônico-etanólicos, sendo essa diferença significativa. Para efeito de comparação, utilizouse o antioxidante sintético BHT e o flavonoide quercetina, que apresentaram uma atividade antioxidante de $0,015 \pm 0,00$ e $0,00198 \pm 0,00002 \mathrm{mg}$ $\mathrm{mL}^{-1}$, respectivamente. Nenhuma das amostras analisadas apresentou atividade antioxidante superior aos antioxidantes sintéticos.
Com exceção da amostra de caju e goiaba in natura, em que não houve diferença significativa entre os extratos, os extratos acetônico-metanólicos apresentaram uma atividade antioxidante equivalente ao trolox, significativamente maior que os extratos acetônico-etanólicos. Em relação à atividade antioxidante equivalente ao ácido ascórbico, apenas as amostras de acerola in natura e polpa congelada, caju polpa congelada e goiaba in natura e polpa congelada apresentaram uma atividade significativamente maior para os extratos acetônico-metanólicos, as demais amostras não apresentaram diferença significativa (Tabela 3).

Os extratos acetônico-etanólicos das polpas de acerola e goiaba apresentaram uma atividade antioxidante equivalente ao trolox, menor que seus respectivos frutos in natura; para os extratos acetônico-metanólicos as polpas congeladas de acerola e caju apresentaram diferença significativa na sua atividade antioxidante em relação aos seus frutos in natura. Para as demais amostras de frutos, não foram observadas diferenças significativas entre o fruto in natura e a polpa congelada.

Os padrões apresentaram uma atividade antioxidante equivalente ao trolox de $1.70212,8 \pm 1.037,58 \mu \mathrm{M}$ trolox $\mathrm{g}^{-1}$ amostra para $\mathrm{o}$ BHT e de $147.601,5 \pm 1.403,94 \mu \mathrm{M}$ troloxg ${ }^{-1}$ amostra para a quercetina, e equivalente ao ácido ascórbico de 21.978,02 $\pm 139,61 \mathrm{mg}$ ácido ascórbico $\mathrm{g}^{-1}$ amostra para o BHT e de 18.518,52 $\pm 128,56 \mathrm{mg}$ ácido ascórbico $\mathrm{g}^{-1}$ amostra para a quercetina. Notase que, quando comparado aos padrões, o potencial antioxidante das amostras é considerado um potencial baixo.

Os compostos fenólicos apresentam em sua estrutura anel aromático com alguns hidrogênios substituídos por hidroxilas, as quais são responsáveis por doar hidrogênio e elétrons para o radical livre. Após a doação do hidrogênio e elétrons, os compostos fenólicos tornam-se um novo radical, porém o anel aromático é capaz de estabilizar o elétron desemparelhado. Dessa forma, o número e a posição das hidroxilas presentes na molécula dos compostos fenólicos é um fator relevante para a atividade antioxidante. Trabalhos de SHAHIDI et al. (1992) observaram que hidroxilas em posição ortodihidroxilação contribuem marcadamente para a atividade antioxidante do composto.

A polaridade do solvente utilizado, tempo e temperatura de extração são fatores que influenciam na extração dos compostos antioxidantes (ANDREO \& JORGE, 2006). O metanol possui uma polaridade superior ao etanol, devido a sua cadeia hidrocarbônica 
Tabela 2 - Determinação da atividade antioxidante pelo método DPPH expresso em IC 50\% (mg mL $\left.\mathrm{m}^{-1}\right)$ em frutos e polpas congeladas de acerola, caju, goiaba e morango.

\begin{tabular}{lcc}
\hline Amostras & Extrato acetônico-etanólico & Extrato acetônico-metanólico \\
\hline Acerola in natura & $0,225 \pm 0,001 \mathrm{~h} \mathrm{~A}$ & $0,179 \pm 0,003 \mathrm{~g} \mathrm{~B}$ \\
Acerola polpa congelada* & $0,286 \pm 0,006 \mathrm{~g} \mathrm{~A}$ & $0,196 \pm 0,000 \mathrm{~g} \mathrm{~B}$ \\
Caju in natura & $1,373 \pm 0,005 \mathrm{e} \mathrm{A}$ & $0,809 \pm 0,006 \mathrm{e} \mathrm{B}$ \\
Caju polpa congelada* & $0,929 \pm 0,007 \mathrm{f} \mathrm{A}$ & $0,742 \pm 0,007 \mathrm{fB}$ \\
Morango in natura & $1,858 \pm 0,014 \mathrm{~d} \mathrm{~A}$ & $1,582 \pm 0,012 \mathrm{~d} \mathrm{~B}$ \\
Morango polpa congelada* & $2,133 \pm 0,005 \mathrm{c} \mathrm{B}$ & $2,152 \pm 0,017 \mathrm{~b} \mathrm{~A}$ \\
Goiaba in natura & $2,569 \pm 0,032 \mathrm{~b} \mathrm{~A}$ & $2,088 \pm 0,019 \mathrm{c} \mathrm{B}$ \\
Goiaba polpa congelada* & $3,913 \pm 0,005 \mathrm{aA}$ & $2,908 \pm 0,013 \mathrm{a} \mathrm{B}$ \\
\hline
\end{tabular}

Médias seguidas da mesma letra minúscula nas colunas e letra maiúscula nas linhas não diferem entre si pelo teste de Scott-Knott a 5\% de probabilidade. Médias \pm desvio padrão de 4 repetições. *Polpas congeladas a $-18^{\circ} \mathrm{C}$ por 3 meses.

ser menor que a do etanol, sendo um solvente mais eficiente para extrair um número maior de compostos antioxidantes com polaridade elevada. Esse fato justifica um número maior de amostras apresentando uma atividade antioxidante significativamente maior nos extratos acetônico-metanólicos. O que pode ser evidenciado pelo trabalho de WU et al. (2004), que, estudando a atividade antioxidante de vários frutos, observaram que a fração hidrofílica apresentou a maior atividade antioxidante pelo método ORAC (capacidade de absorção do radical oxigênio) do que a fração lipofílica. Os mesmo autores ressaltam que os compostos fenólicos das frações hidrofílicas são os responsáveis por mais de $90 \%$ da atividade antioxidante.

Os compostos bioativos presentes nos frutos estão susceptíveis às reações de oxidação que ocorrem durante o seu processamento e estocagem, pois alguns compostos são instáveis (MELO et al., 2008). Períodos prolongados de refrigeração ou temperaturas muito baixas geram uma perda na qualidade dos frutos. Esses danos são devido à ação de enzimas específicas. As enzimas peroxidase e polifenoloxidase participam da oxidação dos compostos fenólicos e, dessa forma, podem diminuir a capacidade antioxidante das polpas congeladas (EDAGI et al., 2009). É evidenciada neste trabalho a redução dos compostos fenólicos e da atividade antioxidante para as polpas congeladas, com exceção.

Para as amostras de caju, foi observado um aumento significativo da atividade antioxidante da polpa congelada em comparação ao fruto in natura. Esse fato pode ser justificado pela ação da enzima fenilalanina amônia-liase e outras enzimas, as quais atuam no metabolismo secundário, formando outros compostos fenólicos (EDAGI et al., 2009).

Tabela 3 - Determinação da atividade antioxidante equivalente ao trolox ${ }^{\circledR}\left(\mu \mathrm{M}\right.$ trolox $\mathrm{g}^{-1}$ de amostra) e equivalente ácido ascórbico (mg ácido ascórbico $\mathrm{g}^{-1}$ amostra) em frutos e polpas congeladas de acerola, caju, goiaba e morango.

\begin{tabular}{|c|c|c|c|c|}
\hline \multirow[b]{2}{*}{ Amostras } & \multicolumn{2}{|c|}{---------------( $\mu \mathrm{M}$ trolox g ${ }^{-1}$ de amostra)-------------- } & \multicolumn{2}{|c|}{------- (mg ácido ascórbico g ${ }^{-1}$ amostra) ------ } \\
\hline & $\begin{array}{l}\text { Extrato acetônico- } \\
\text { etanólico }\end{array}$ & $\begin{array}{l}\text { Extrato acetônico- } \\
\text { metanólico }\end{array}$ & $\begin{array}{l}\text { Extrato acetônico- } \\
\text { etanólico }\end{array}$ & $\begin{array}{l}\text { Extrato acetônico- } \\
\text { metanólico }\end{array}$ \\
\hline Acerola in natura & $1.336,42 \pm 18,45 \mathrm{a} \mathrm{B}$ & $1.823,52 \pm 72,58 \mathrm{aA}$ & $219,98 \pm 3,35$ a B & $305,78 \pm 11,80 \mathrm{aA}$ \\
\hline Acerola polpa congelada* & $1.298,14 \pm 9,62 \mathrm{~b} \mathrm{~B}$ & $1.442,07 \pm 26,44 \mathrm{~b} \mathrm{~A}$ & $217,51 \pm 1,78$ a B & $242,14 \pm 7,26$ b A \\
\hline Caju in natura & $254,34 \pm 2,82 \mathrm{c} \mathrm{A}$ & $269,49 \pm 2,95 \mathrm{~d} \mathrm{~A}$ & $42,19 \pm 0,52 \mathrm{~b} \mathrm{~A}$ & $45,00 \pm 0,57 \mathrm{~d} \mathrm{~A}$ \\
\hline Caju polpa congelada* & $250,02 \pm 2,31 \mathrm{c} \mathrm{B}$ & $374,34 \pm 7,26 \mathrm{c} \mathrm{A}$ & $40,41 \pm 1,73$ b B & $62,78 \pm 1,37 \mathrm{c} \mathrm{A}$ \\
\hline Morango in natura & $199,82 \pm 8,18 \mathrm{~d} \mathrm{~B}$ & $261,77 \pm 2,28 \mathrm{~d} A$ & $44,24 \pm 2,67 \mathrm{~b} \mathrm{~A}$ & $43,48 \pm 0,38 \mathrm{~d} A$ \\
\hline Morango polpa congelada* & $192,73 \pm 3,48 \mathrm{~d} B$ & $242,67 \pm 4,93 \mathrm{~d} A$ & $36,66 \pm 8,24 \mathrm{~b} \mathrm{~A}$ & $40,21 \pm 1,05 \mathrm{~d} A$ \\
\hline Goiaba in natura & $130,77 \pm 2,41$ e $\mathrm{A}$ & $151,79 \pm 3,56$ e A & $15,95 \pm 0,46 \mathrm{~d} B$ & $24,90 \pm 0,64$ e $\mathrm{A}$ \\
\hline Goiaba polpa congelada* & $96,10 \pm 3,39 \mathrm{f} \mathrm{B}$ & $152,79 \pm 2,26$ e A & $22,62 \pm 2,41 \mathrm{c} \mathrm{B}$ & $29,21 \pm 0,55$ e $A$ \\
\hline
\end{tabular}

Médias seguidas da mesma letra minúscula nas colunas e letra maiúscula nas linhas não diferem entre si pelo teste de Scott-Knott a $5 \%$ de probabilidade. Médias \pm desvio padrão de 4 repetições. *Polpas congeladas a $-18^{\circ} \mathrm{C}$ por 3 meses. 


\section{CONCLUSÃO}

As polpas congeladas dos frutos apresentaram teores de compostos fenólicos semelhantes aos dos frutos in natura, com exceção da polpa congelada de acerola. Houve uma redução no teor de ácido ascórbico para as polpas congeladas de acerola e goiaba, os demais frutos não apresentaram diferença significativa.

Entre os valores de IC 50\% para a atividade antioxidante pelo método de inativação do radical DPPH, a atividade antioxidante foi significativamente maior para os extratos acetônico-metanólicos, quando comparados aos extratos acetônico-etanólicos, com exceção da polpa congelada de morango. Por essa mesma metodologia, pode-se concluir, com exceção das amostras de caju e do extrato acetônico-etanólico da acerola, que as amostras in natura apresentaram a maior atividade antioxidante.

Comparando os dois tipos de extratos, os valores TEAC e VCEAC mostram valores coerentes em relação à atividade antioxidante pelo método DPPH, com exceção para as amostras de goiaba e caju in natura, pelo método TEAC e amostras de caju e morango in natura e morango polpa congelada. Houve uma redução da atividade antioxidante das polpas congeladas em relação aos frutos in natura, e somente significativa para alguns casos. Porém, os extratos acetônico-metanólicos das polpas congeladas de caju para o TEAC e o extrato acetônico-etanólico da goiaba para o VCEAC apresentaram um aumento significativo.

As amostras de acerola apresentaram os melhores resultados, sendo, assim, a de maior atividade antioxidante dentre as demais amostras.

\section{AGRADECIMENTOS}

Ao Conselho Nacional de Desenvolvimento Científico e Tecnológico (CNPq), Coordenação de Aperfeiçoamento de Pessoal de Nível Superior (CAPES) e Fundação de Amparo à Pesquisa do estado de Minas Gerais (FAPEMIG), pelo apoio financeiro.

\section{REFERÊNCIAS}

ANDREO, D.; JORGE, N. Antioxidantes naturais: técnicas de extração. Boletim do Centro de Pesquisa de Processamento de Alimentos, v.24, n.2, p.319-326, 2006. Disponível em: $<$ http://ojs.c3sl.ufpr.br/ojs-2.2.4/index.php/alimentos/article/ viewArticle/7489>. Acesso em: 09 mar. 2013.

AOAC (ASSOCIATION OFFICIAL ANALYTICAL CHEMISTRY). Official methods of analysis of the Association of Official Analytical Chemistry. 12.ed. Washington, 2005. 1015p.

EDAGI, F.K. et al. Aumento do potencial de armazenamento refrigerado de nêsperas 'Fukuhara' com o uso de tratamento térmico. Pesquisa Agropecuária Brasileira, v.44, n.10, p.12701276, 2009. Disponível em: <http://www.scielo.br/scielo. php?script $=$ sci_arttext\&pid=S0100204X2009001000009\&lang $=\mathrm{pt}>$. Acesso em: 09 mar. 2013. doi http://dx.doi.org/10.1590/ S0100-204X2009001000009.

GOLDSTEIN, J.L.; SWAIN, T. Changes in tannins in ripening fruits. Phytochemistry, v.2, p.371-383, 1963.

GOMES, J.E. et al. Análise de agrupamentos e de componentes principais no processo seletivo em genótipos de aceroleira (Malpighia emarginata D.C.). Revista Brasileira de Fruticultura, v.22, n.1, p.36-39, 2000.

KUSKOSKI, E.M. et al. Frutos tropicais silvestres e polpas congeladas: atividade antioxidante, polifenóis e antocianinas. Ciência Rural, v.36, n.4, p.1283-1287, 2006. Disponível em: $<$ http://www.scielo.br/pdf/cr/v36n4/a37v36n4.pdf $>$. Acesso em: 08 nov. 2012. doi: 10.1590/S0103-84782006000400037.

LIMA, E.S. et al. Redução de vitamina C em suco (Anacardium occidentale L.) industrializado e cajuína. Química Nova, v.30, n.5, p.1143-1146, 2007. Disponível em: <http://www.scielo.br/pdf/qn/ v30n5/a17v30n5.pdf>. Acesso em: 08 nov. 2012. doi:10.1590/ S0100-40422007000500017.

MELO, E.A. et al. Teor de fenólicos totais e capacidade antioxidante de polpas congeladas de frutas. Alimento e Nutrição, v.19, n.1, p.6772, 2008. Disponível em: <http://serv-bib.fcfar.unesp.br/seer/index. php/alimentos/article/view/202/207>. Acesso em: 08 nov. 2012.

PIMENTEL, M. et al. Influência do processamento sobre a vitamina $\mathrm{C}$ do suco da acerola (Malpighia glabra L.). Revista Brasileira de Fruticultura, v.23, n.1, p.143-146, 2001.

ROCHA, D.A. et al. Análise comparativa de nutrientes funcionais em morangos de diferentes cultivares da região de Lavras-MG. Revista Brasileira de Fruticultura, v.30, n.4, p.1124-1128, 2008. Disponível em: <http://www.scielo.br/pdf/rbf/v30n4/ a46v30n4.pdf>. Acesso em: 08 nov. 2012. doi: 10.1590/S010029452008000400046.

RUFINO, M.S.M. et al. Metodologia cientifica: determinação da atividade antioxidante total em frutos pela captura do radical livre ABTS. Fortaleza: EMBRAPA, 2007. (Comunicado técnico).

SHAHIDI, F. et al. Phenolic antioxidants. CRC Critical. Reviews in Food Science and Nutrition, v.32, n.1, p.67-103, 1992.

SILVA, P.A. et al. Desenvolvimento de metodologia analítica para determinação de vitamina C em morangos por HPLC. In: REUNIAO ANUAL DA SOCIEDADE BRASILEIRA DE QUÍMICA, 32., 2009, Fortaleza, CE. Anais... Fortaleza: SBQ, 2009. 1CD-ROOM.

STROHECKER, R.; HENNIG, H.M. Análises de vitaminas: métodos comprovados. Madrid: Paz Montalvo, 1967. 428p.

THAIPONG, K. et al. Comparison of ABTS, DPPH, FRAP and ORAC assays for estimating antioxidant activity from guava fruit extracts. Journal of Food Composition and Analysis, v.19, p.669-675, 2006. Disponível em: <http://pirun.ku.ac.th/ agrkst/ Comparison\%20AOA_guava.pdf $>$. Acesso em: 08 nov. 2012.

WU, X. et al. Lipophilic and hydrophilic antioxidant capacities of common foods in the United States. Journal of Agricultural and Food Chemistry, v.52, n.12, p.4026-4037, 2004. 